\title{
Investigation of dietary factors in migraineurs.
}

\author{
Hongjin Li, Yingbo Zhang, Qiang Li, Yingying Li, Xiaojun Diao and Chunfu Chen \\ Shandong Provincial Hospital Affiliated to Shandong University, Jinan, China.
}

Key words: migraine; tension-type headache; eating habits; food-induced factors.

\begin{abstract}
We conducted the current study to investigate migraine-related dietary factors in migraine patients. Seventy patients with migraine and 30 patients with tension-type headache were enrolled in the study, recruited from the headache outpatient department of the Shandong Provincial Hospital from June 2014 to May 2016. The average age of the migraine group was 15 to 60 years with an average of $35.5 \pm 13.8$ years, including 23 males and 47 females (1: 2.04 male to female ratio). The age of patients with tension-type headache ranged from 18 to 60 years-old with an average of $35.4 \pm 14.4$ years, including 13 males and 17 females (1: 1.31 male to female ratio). The headache was graded based on the severity and frequency of the episodes, according to the ICHD-II diagnostic criteria, during symptom intermission. The results were analyzed with the SPSS 21.0 software. Thirty migraine patients (42.9\%) and three tension-type headache patients $(10.0 \%)$ presented diet-induced factors. There was a significant difference $(\mathrm{p}<0.05)$. The difference in rates of foodinduced factors between migraine patients with aura and migraine patients without aura was statistically significant $(p<0.05)$, and food-induced factors are more common in migraine patients with aura. The most common foodinduced factor in males was alcohol while the food-induced factors in female varied more. Both, the headache frequency and severity in migraine patients with food-induced factors, were higher than those in migraine patients without food-induced factors $(p<0.05)$, but the difference in the headache duration was not statistically significant $(p>0.05)$.
\end{abstract}

Corresponding Author: Chunfu Chen, Shandong Provincial Hospital Affiliated to Shandong University, Jinan 250021, China. Tel:+86-053168776354; Email: chenchunfu_1@aliyun.com 


\section{Investigación de factores dietéticos en personas con migraña.} Invest Clin 2020; 61 (1): 21-29

Palabras clave: migrañas; migrañas nerviosas; hábitos alimentarios; incentivos alimentarios.

Resumen. El estudio se realizó para investigar los factores alimentarios relacionados con la migraña en los pacientes que sufren este trastorno. Se escogieron 70 casos de migrañas y 30 casos de cefaleas de tipo tensional, entre junio de 2014 y mayo de 2016, reclutados de la Clínica de Jaqueca del hospital provincial de Shandong. La edad media de los grupos de migrañas osciló entre los 15 y los 60 años, con un promedio de 35,5 $\pm 13,8$ años, de los cuales 23 fueron hombres y 47 mujeres (1: 2,04 ratio). Los casos de cefalea de tipo tensional tenían entre 18 y 60 años, con un promedio de 35,4 $\pm 14,4$ años, de los cuales 13 eran hombres y 17 mujeres (1: 1,31 ratio). Los dolores de cabeza se clasificaron en función de la gravedad y la frecuencia con arreǵlo a los criterios de diaǵnóstico del ICHD - II para el intervalo sintomático. Los resultados se analizaron con el programa informático SPSS 21.0. Se encontraron factores alimentarios inductores en 30 casos de migraña $(42,9 \%)$ y en tres casos de cefalea de tipo tensional $(10,0 \%)$. La diferencia fue significativa $(\mathrm{p}<0,05)$. Hubo una diferencia estadísticamente significativa entre la incidencia de los factores inductores alimentarios entre las personas con migrañas con aura y las personas con migrañas sin aura $(\mathrm{p}<0,05)$. Estos factores fueron más comunes entre las personas que presentaban migrañas con aura. El factor alimentario inductor más común entre los hombres fue el alcohol, mientras que en las mujeres fue más variable. Tanto la frecuencia de la cefalea como su severidad, fueron mayores en pacientes con migraña con factores alimentarios inductores que en pacientes sin estos factores inductores $(\mathrm{p}<0,05)$, pero la diferencia en la duración de la cefalea no fue estadísticamente significativa $(\mathrm{p}>0,05)$.

Received: 18-02-2019 Accepted: 06-02-2020

\section{INTRODUCTION}

Studies have shown that about $85 \%$ of migraineurs have spoken about its precipitating factors. Common aǵgravating factors include mental stress, weather change, anxiety and depression, mood swing, insomnia, overwork, stimulation by sound, light and taste, hunger and diet (1), etc. Among these aggravating factors, dietary factors are very common. The major reported diet-induced factors in clinical practice include irregular eating and food-induced factors, that is, if migraine occurs within a particular period of time (often within $24 \mathrm{~h}$ and generally no more than 48h) after food intake, all these particular foods are called food-induced factors (2). In previous studies, the rates of all kinds of diet-induced factors had a wide range, from $12 \%$ to $60 \%$ (3-7), but significantly higher than in other types of headache. For patients with diet-induced factors, if they can effectively identify and prevent such factors, it may help to improve the control of migraine. 
Migraine is defined as the recurring headaches usually involving one side of the head, which are often accompanied by nausea and visual disturbances, and can be divided into two major sub-types, migraine without aura and migraine with aura. The tension-type headache is characterized by a diffuse, mild to moderate pain in your head and is often described as feeling a tight band around your head, and is the most common type of primary headache (4). The characters of tension-type headache are blunt ache, tenderness on your scalp, neck and shoulder muscles, blurred vision and tinnitus. Its pathogenesis is realated to psychological stress, anxiety, depression, mental factors, muscle tension and abuse of analgesic drugs (5). However, the relationship between the common primary headache and dietary induced factors has not been reported. We mainly investigated the food-induced factors such as drinks, staple food, fruits and vegetables, seasoning in daily diet of local patients. In addition, dietary regularity was also investigated. The irregular eating refers to poor eating habits, such as fasting, overeating, abuse and withdrawal. Therefore, we conducted an epidemiological investigation to research the effect of diet-induced factors on different types of headache and the two sexes, which will provide a theoretical basis for non-drug prevention of migraine.

\section{STUDY SUBJECTS AND METHODS}

\section{Research Subjects}

All headache patients in this study were selected from patients who were confirmed, treated and enrolled in the headache outpatient department of the Shandong Provincial Hospital from June 2014 to May 2016, including 70 migraine patients and 30 tension-type headache patients, with half a year course of this disease. All of the patients involved in our study voluntarily agreed and signed an informed consent form, which was approved by the ethics committee.
In the migraine group, the age ranged from 15 to 60 years with an average of 35.5 \pm 13.8 years, including 23 males and 47 females (1: 2.04 male to female ratio). There were 15 migraine patients with aura and $\mathbf{5 5}$ migraine patients without aura. The age of the tension-type headache patients ranged from 18 to 60 years-old with an average of $35.4 \pm 14.4$ years, including 13 males and 17 females (1: 1.31 male to female ratio).

\section{Inclusion and Exclusion Criteria \\ Inclusion Criteria}

Positively diagnosed based on the diagnostic criteria about migraine without aura, migraine with aura, chronic migraine and tension-type headache of the International Classification of Headache Disorders 2nd Edition, ICHD-II issued by International Headache Society in $2004(9,10)$.

\section{Exclusion Criteria}

(1) Menstruation-related migraine, coexistence of various types of headaches, secondary headaches and neuralgia.

(2) Patients with serious systemic diseases or suffering from other chronic diseases.

(3) Patients with a history of intracranial infection, craniocerebral trauma and/or other craniocerebral organic diseases.

(4) Drug addicts or drug abusers.

(5) Patients taking oral contraceptives, pregnant or lactating women.

(6) Patients who declined to participate and patients who still cannot complete relevant questionnaires under the guidance.

\section{Data Collection}

A questionnaire (8) was used to collect general information and detailed conditions of patients in line with the criteria. The information of patient was provided by the patients themselves and/or their families. All of the patients kept headache diaries and were then followed up at 3 and 6 months. All information was collected and collated in the process of initial or follow-up visits,

Vol. 61(1): 19 - 27, 2020 
and the proportion of patients with irregular eating was collected. The questionnaire was open-ended, and the possible food-induced factors in the questionnaire included drinks, grains, meat, fruits, vegetables, condiments and other products. Irregular eating included fasting, withdrawal and overeating. All foods should have been taken as main meals between 6 am and $8 \mathrm{pm}$. All the physical objects are purchased in the regular supermarket market. In addition, all food was not special. All information was collected and collated in the process of initial or follow up visits every 2 months.

\section{Headache Grading}

Grading was performed on headache severity by combing the patients' clinical manifestations, characteristics of headache and the score of Visual Analogue Scale (VAS) and referring to 1995 Migraine Diagnostic Efficacy Evaluation Standard Opinions (9).

\section{Statistical Analysis}

Statistical analysis was performed in SPSS 21.0 (IBM, White Plains, New York, USA). Parametric data was expressed as mean \pm standard deviation $(\bar{x} \pm s)$. The comparison of enumeration data between the migraine group and tension-type headache group was conducted used chi-square test; the comparison of enumeration data within the migraine group used nonparametric independent sample rank-sum test and that of measurement data adopted two independent sample $t$-test. Statistical significance was defined as $p<0.05$.

\section{RESULTS}

\section{General Data}

This study included 70 patients with migraine and the ratio of male and female ratio was $23: 47$, which is in line with the ratio of incidence rate of our country's male and female patients with migraine. The study group included 15 migraine patients with aura and $\mathbf{5 5}$ migraine patients without aura. Among them, there were two patients with mild headache (2.9\%), 25 patients with moderate headache (35.7\%) and 43 patients with severe headache (61.4\%). Their ages were $35.5 \pm 13.8$ (15 $60)$ years and their course of disease duration was $10.9 \pm 8.2(2 \sim 35)$ years. There were 30 tension-type headache patients in total and the ratio of male to female was $13 / 17$; their ages were $35.4 \pm 14.3(18 \sim 60)$ years and their course of the disease was $11.7 \pm$ $9.9(0.5 \sim 33)$ years. The comparative difference of the migraine group and tension-type headache group in gender, age and course of the disease was of no statistical significance $(p>0.05)$. The two groups of patients were comparable.

\section{Irregular Eating}

The rates of irregular eating of migraine group and tension-type headache group were $31.4 \%(22 / 70)$ and $10.0 \%(3 / 30)$, respectively. The rate of migraine patients with irregular eating habits was significantly higher than that of patients with tension-type headache $(p=0.025)$.

The rates of irregular eating of male and female in migraine group were $30.4 \%$ $(7 / 23)$ and $31.9 \%(15 / 47)$, respectively, and the difference was not statistically significant $(p=1.000)$.

The rates of irregular eating in migraine patients with aura and migraine patients without aura were $46.7 \%(7 / 15)$ and $27.3 \%(15 / 55)$, and the difference was not statistically significant $(p=0.210)$.

The rates of food-induced factors in migraine group and tension-type headache group were $17.1 \%(12 / 70)$ and $0(0 / 30)$ and the difference was statistically significant $(p$ $=0.016)$, which indicates that food-induced factors are fairly common in migraine patients but rare in tension-type headache patients.

The rates of food-induced factors in male and female patients of migraine group were $21.7(5 / 23)$ and $14.9 \%(7 / 47)$, respectively, and the difference was not statistically significant $(p=0.511)$. 
The rates of food-induced factors in migraine patients with aura and migraine patients without aura were $40.0 \%(6 / 15)$ and $10.9 \%(6 / 55)$, respectively, and the difference was statistically significant $(p$ $=0.016)$, which indicates that migraine patients with aura are prone to have foodinduced factors.

Reported food-induced factors in migraine group include: alcohol $(n=6)$, coffee $(n=2)$, chocolate $(n=2)$, salt $(n=1)$, banana $(n=1)$, fat meat $(n=1)$, soy sauce $(n=1)$, cake $(n=1)$, corn $(n=1)$ (including 1 female patient simultaneously had two types of food-induced factors: coffee and chocolate; 1 female patient simultaneously had 4 types of food-induced factors: banana, fat meat, soy sauce and cake). The most common food-induced factor in male patients was alcohol, while the food-induced factors in female patients were diverse, including coffee, chocolate, banana, fat meat, soy sauce, cake and corn. The composition of food-induced factors is shown in Fig. 1 and Fig. 2.

\section{Relationship between Irregular Eat- ing and Migraine Indexes \\ Among the 70 migraine patients, 48} had regular eating and the other 22 had irregular eating habits. Rank sum test for the attack frequency, duration and pain severity was performed in these two groups of patients, and the test results are shown in Table I. The difference in attack frequency between two groups of patients was statistically significant $(p<0.001)$, but the differences in the headache duration $(p=0.334)$ and in the severity of pain $(p=0.609)$ were not statistically significant. This indicates that compared with migraine patients with regular eating, migraine patients with irregular eating are more vulnerable to suffer migraine attacks, but there was no difference in migraine duration and pain severity between the two groups. However, among the 22 migraine patients with irregular eating in this study, no patient reported that the migraine attack had a close temporal relationship with irregular eating (including fasting, dieting, long intervals between meals, etc.).

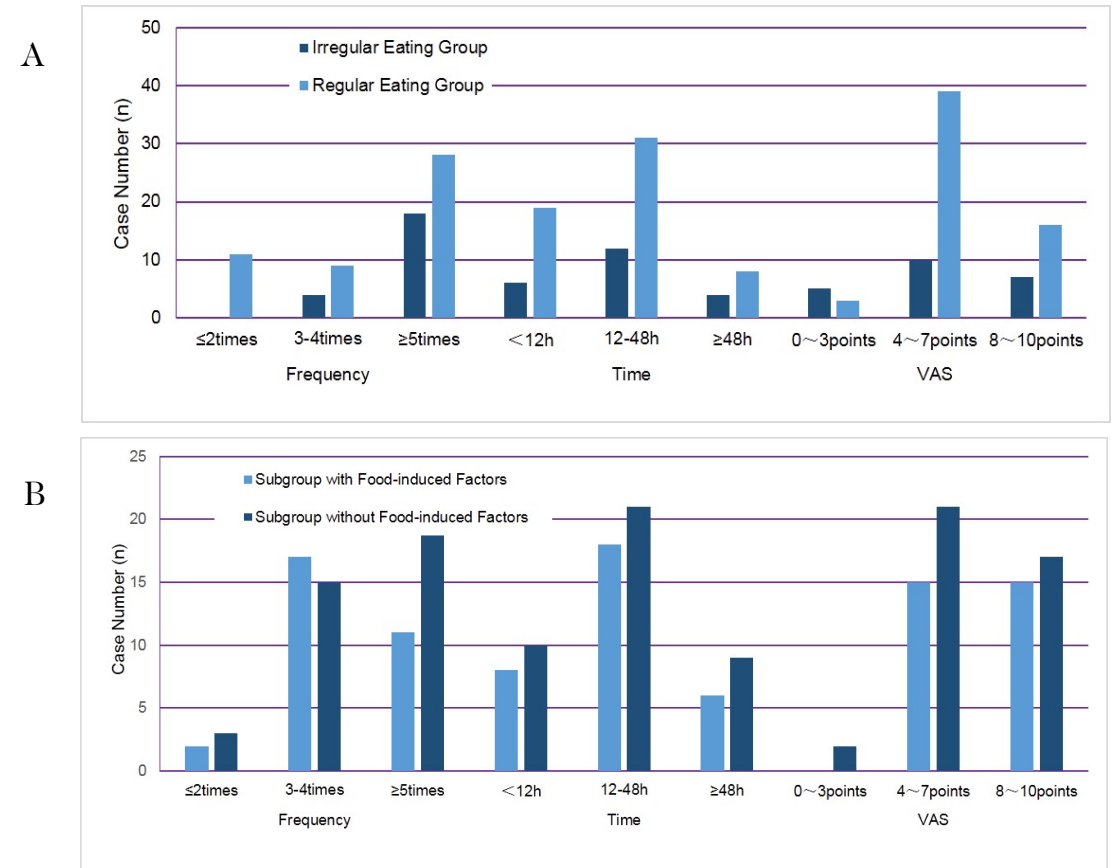

Fig. 1. Food-induced Factors of Migraine Patients and their Incidence Rates. 


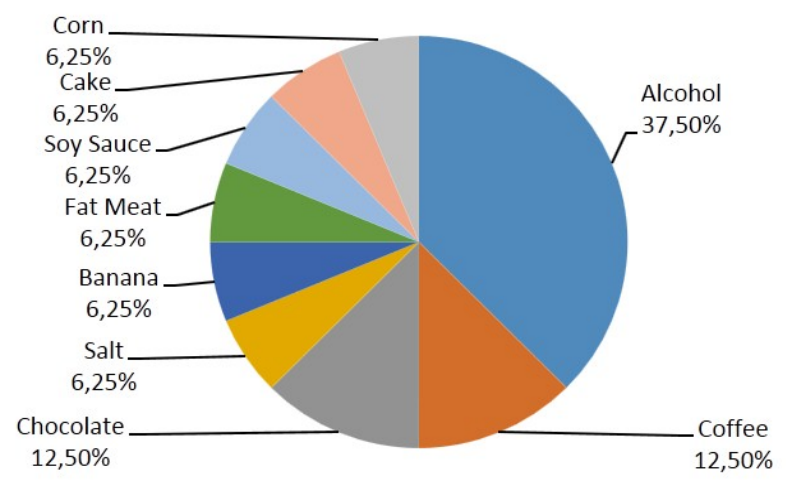

Fig. 2. Composition Ratio of Different Food-induced Factors. The most common food-induced factor in male patients was alcohol, while the food-induced factors in female patients were diverse, including coffee, chocolate, banana, fat meat, soy sauce, cake and corn.

TABLE I

INFLUENCE OF REGULAR EATING ON MIGRAINE INDEXES $(\overline{\mathrm{x}} \pm s)$

\begin{tabular}{lcccc}
\hline Headache Indexes & $\begin{array}{c}\text { Irregular Eating Group } \\
(\mathrm{n}=22)\end{array}$ & $\begin{array}{c}\text { Regular Eating Group } \\
(\mathrm{n}=48)\end{array}$ & $\mathrm{Z}$ & $\mathrm{P}$ \\
\hline Attack Times per Month & $15.82 \pm 10.81$ & $9.36 \pm 11.77$ & -3.488 & $<0.001$ \\
Duration (h) & $17.00 \pm 15.52$ & $17.64 \pm 18.95$ & -0.966 & 0.334 \\
Headache Severity & $6.95 \pm 2.34$ & $5.55 \pm 1.68$ & -0.512 & 0.609 \\
\hline
\end{tabular}

Relationship between Food-induced Factors and Migraine Indexes

Migraine patients were divided into two subgroups: one subgroup migraine patients with food-induced factors and another migraine patient without food-induced factors. Rank sum test for the attack frequency, duration and pain severity was performed in these two subgroups of patients, and the results are shown in Table II. The difference in the headache attack frequency between these two subgroups of patients was statistically significant ( $p=0.048)$; the difference in duration was not statistically significant $(p=0.651)$; the difference in pain severity was statistically significant $(p=0.033)$. This indicates that migraine patients with food-induced factors are more likely to have migraine attacks than those without foodinduced factors, and experience more severe attacks than those without food-induced factors, but these two subgroups have no significant differences in the duration of migraine attacks.

\section{Diet-induced Factors and Headache Severity}

Migraine patients were divided into two groups according to migraine diagnosis and efficacy scoring criteria for assessment, patients with diet-induced factors and patients without diet-induced factors by grade in accordance with the headache severity. Rank-sum test were performed for headache patients with different severity. There was obvious difference in migraine severity between two groups $(p<0.001)$ and the patients with diet-induced factors are more likely to have severer headache. The results are shown in Table III.

\section{Diet-induced Factors and Migraine Chronification}

Among patients in the migraine group, there were 43 paroxysmal migraine patients and 27 chronic migraine patients. The differences in the rate of eating habits $\left(\chi^{2}=\right.$ $1.769, p=0.199)$, food-induced factors $\left(\chi^{2}\right.$ $=0.059, p=1.000)$ of these two types of 
TABLE II

INFLUENCE OF FOOD-INDUCED FACTORS ON MIGRAINE INDEXES ( $\overline{\mathrm{x} \pm \mathrm{s})}$

\begin{tabular}{lcccc}
\hline Headache Indexes & $\begin{array}{c}\text { Subgroup with Food- } \\
\text { induced Factors } \\
(\mathrm{n}=30)\end{array}$ & $\begin{array}{c}\text { Subgroup without Food- } \\
\text { induced Factors } \\
(\mathrm{n}=40)\end{array}$ & $\mathrm{Z}$ & $\mathrm{P}$ \\
\hline Attack Times per Month & $14.67 \pm 10.25$ & $13.71 \pm 11.87$ & -1.980 & 0.048 \\
Duration (h) & $23.25 \pm 21.55$ & $20.36 \pm 18.61$ & -0.452 & 0.651 \\
Headache Severity & $7.92 \pm 2.23$ & $6.43 \pm 1.96$ & -2.137 & 0.033 \\
\hline
\end{tabular}

TABLE III

HEADACHE SEVERITY OF MIGRAINE PATIENTS WITH AND WITHOUT DIET-INDUCED FACTORS ( $n$ )

\begin{tabular}{lcccc}
\hline \multirow{2}{*}{ Group } & \multicolumn{3}{c}{ Migraine Severity } & Total \\
\cline { 2 - 5 } & Mild & Moderate & Severe \\
\hline With diet-induced factors & 0 & 6 & 24 & 30 \\
Without diet-induced factors & 2 & 19 & 19 & 40
\end{tabular}

By comparison between two groups, $P<0.001$.

TABLE IV

RELATIONSHIP OF DIET-INDUCED FACTORS AND THEIR ANOREXIA SYMPTOMS WITH MIGRAINE MODERATION TRANSFORMATION

\begin{tabular}{lcccccccc}
\hline \multirow{2}{*}{ Group } & & \multicolumn{2}{c}{ Eating Habits } & Food-induced Factors & \multicolumn{2}{c}{ Anorexia } \\
\cline { 3 - 8 } & & Regular & Irregular & No & Yes & No & Yes \\
\hline paroxysmal migraine & 43 & 32 & 11 & 36 & 7 & 21 & 22 \\
chronic migraine & 27 & 16 & 11 & 22 & 5 & 14 & 13 \\
\hline
\end{tabular}

patients were not statistically significant, which indicates that diet-induced factors may not play a role in migraine moderation. The results are shown in Table IV.

\section{DISCUSSION}

Dietary factors in migraine is a complex topic. About 55 years ago, Selby and Lance observed that migraine attacks in a proportion of patients were usually precipitated by dietary items (10). Subsequently, studies reported the percentage of patients reporting foods as a trigger for migraine ranged from 12 to $60 \%$, with many subjects reporting more than one factor (11-14). Avoidance of specific foods (e.g., alcohol, cheese, chocolate, sauce, monosodium glutamate, aspartame, some fruits and milk) may be helpful, but it is difficult to completely avoid them because they are widely used in restaurants and home cooking. Such factors are not well studied in China. The diet-induced factors of migraine and their characteristics of "can be found, can be controlled, economically and safely" have become an entry point of current studies of environmental factors of migraine as well as the prevention and therapeutic research of migraine (14). A number of clinical studies have shown that conducting diet control for patients with migraine can significantly help relieve migraine pa- 
tients' condition $(4,7,10,12)$, which makes diet control for migraine patients an important component in non-drug therapy.

The mechanism by which dietary factors induce migraine attacks is not clear, but it may be related to the following possibilities: (a) some dietary factors, such as alcohol and coffee, directly cause intracerebral vasodilation. (b) By changing some neurotransmitters, such as the contents of catecholamines, 5-HT, glutamic acid, etc., in the central nervous system, or by affecting nitric oxide (NO) synthetic system in vivo and then causing dysfunction in vasoconstriction (1). (c) Certain eating habits or diets can cause the imbalance of nutrients, such as lack of $\mathrm{Mg}^{2+}$, riboflavin and coenzyme-Q10, thereby causing metabolic dysfunction, affecting the information processing of neurons and lowering the threshold of migraine attack (15). (d) Some studies suggest that food intolerance is also involved in the diet mechanism of migraine. It can lead to vasodilation and induce migraine by inducing mast cell degranulation to release histamine or activate complements, etc.; it also can produce a series of inflammatory reactions by activating $\mathrm{T}_{\mathrm{h}}$ and $\mathrm{B}$ lymphocytes, and thus triggers migraine (16). (e) Some foods, such as salmon $\backslash$ bean products, may affect the hormonal status of the patients, especially estrogen homeostasis, which may be associated with menstrual-related headaches (17).

Studies and data from China regarding dietary factors in migraine are sparse. The rate of migraine-related dietary factors in this study is lower than those reported in other countries. In addition, in studies conducted in other countries, there are also many patients simultaneously with a variety of diet-induced factors, which may be considered to be related to the following factors: (a) differences in geography, economic status and education level will have an impact on the dietary structure; (b) the identification of food-induced factors is very complex. At present, in various studies from other countries, there are several methods to identifying food-induced factors $(1,5,18$ $20)$, but none of these methods can effectively recognize diet-induced factors of migraine with simplicity, thus reducing the accuracy; (c) other environmental factors are often involved in migraine, which increases the difficulty of identifying dietary factors; (d) the sample size of this study is relatively small, and the quantitative classification adopted for all indexes of migraine lacks much standard references. And the present study cannot exclude the implications that dietary factors avoidance list brings for patients.

Our data show that there is a relevant association between the onset of the headache and diet in China. The results suggest the need to conduct a much larger study to produce more conclusive findings on the relationship between dietary factors and migraine. Considering the small sample size of this study, it is not enough to further explore the influence of more aspects of food and the relationship between specific food triggers/dietary patterns and migraine occurrence in a broader area.

\section{FUNDING}

Scientific Development Plan Project of Shandong Province (2014GSF118005).

\section{REFERENCES}

1. Mollaoğlu M. Trigger factors in migraine patients .Health Psychol 2013, 18(7): 984994.

2. Sun-Edelstein C, Mauskop A. Foods and supplements in the management of migraine headaches. Clin J Pain 2009, 25(5):446452.

3. Kelman L. The triggers or precipitants of the acute migraine attack. Cephalalgia 2007, 27(5):394-402.

4. Carod-Artal FJ, Ezpeleta D, Martı'n-Barriga ML, Guerrero AL. Triggers, symptoms, and treatment in two populations of migraneurs in Brazil and Spain. A cross-cultural study. Neurology 2001, 304(1-2):25-28. 
5. Fukui PT, Gonçalves TR, Strabelli CG, Lucchino NM, Matos FC, Santos JP, Zukerman E, Zukerman-Guendler V, Mercante JP, Masruha MR, Vieira DS, Peres MF. Trigger factors in migraine patients. Arq Neuropsiquiatr 2008, 66(3-A):494-499.

6. Hauge AW, Kirchmann M, Olesen J. Trigger factors in migraine with aura. Cephalalǵia 2010, 30(3):346-353.

7. Andress-Rothrock D, King W, Rothrock J. An analysis of migraine triggers in a clinic-based population. Headache 2010, 50(8):1366-1370.

8. Saraceo MG, Calabrese G, Cavallini M. Relationship between primary headache and nutrition: a questionnaire about dietary habits of patients with headache. Neurol Sci 2014, 35 (1):159-161.

9. Zenghua S, Yang Y. Maǵraine diagnosis. Standard opinions on curative effect evaluation.J Apoplexy Nerv Dis 1995,12(2): 561-565.

10. Selby G, Lance JW. Observations on 500 cases of migraine and allied vascular headache. J Neurol Neurosurg Psychiatry 1960, 23:23-32.

11. Rose FC. Trigger factors and natural history of migraine. Funct Neurol 1986,1:379-384.

12. Van den Berghh V, Amery WK, Waelkens J. Trigger factors in migraine: a study conducted by the Belgian Migraine Society. Headache 1987, 27:191-196.
13. Fukui PT1, Gonçalves TR, Strabelli CG, Lucchino NM, Matos FC, Santos JP, Zukerman E, Zukerman-Guendler V, Mercante JP, Masruha MR, Vieira DS, Peres MF. Trigger factors in migraine patients. Arq Neuropsiquiatr 2008, 66(3A):494-499.

14. Finocchi C, Sivori G. Food as trigger and aǵgravating factor of migraine. Neurol Sci 2012;33:S77-80.

15. Yorns WR Jr, Hardison HH. Mitochondrial dysfunction in migraine. Semin Pediatr Neurol 2013; 20(3):188-193.

16. Aydinlar EI, Dikmen PY. IggG-based elimination diet in migraine plus irritable bowel syndrome. Headache 2013; 53(3):514-525.

17. Mathew PG, Dun EG, Luo JJ. A cyclic pain: the pathophysiology and treatment of menstrual migraine. Obstet Gynecol Surv 2013; 68:130-140.

18. Rockett FC, de Oliveira VR, Castro K. Dietary aspects of migraine trigger factors. Nutr Rev 2012; 70(6):337-356.

19. Martin VT, Behbehani MM. Toward a rational understanding of migraine trigger factors. Med Clin North Am 2001; 85(4):911941.

20. Rees T, Watson D, Lipscombe S. A prospective audit of food intolerance among migraine patients in primary care clinical practice. Headache Care 2005; (2):105110. 